\title{
Neocortical Networks Entrain Neuronal Circuits in Cerebellar Cortex
}

\author{
Hana Roš, ${ }^{1,2 *}$ Robert N. S. Sachdev, ${ }^{1,2 *}$ Yuguo Yu, ${ }^{1,2}$ Nenad Šestan, ${ }^{1,2}$ and David A. McCormick ${ }^{1,2}$ \\ ${ }^{1}$ Department of Neurobiology, School of Medicine, and ${ }^{2}$ Kavli Institute for Neuroscience, Yale University, New Haven, Connecticut 06520
}

Activity in neocortex is often characterized by synchronized oscillations of neurons and networks, resulting in the generation of a local field potential (LFP) and electroencephalogram. Do the neuronal networks of the cerebellum also generate synchronized oscillations and are they under the influence of those in the neocortex? Here we show that, in the absence of any overt external stimulus, the cerebellar cortex generates a slow oscillation that is correlated with that of the neocortex. Disruption of the neocortical slow oscillation abolishes the cerebellar slow oscillation, whereas blocking cerebellar activity has no overt effect on the neocortex. We provide evidence that the cerebellar slow oscillation results in part from the activation of granule, Golgi, and Purkinje neurons. In particular, we show that granule and Golgi cells discharge trains of single spikes, and Purkinje cells generate complex spikes, during the "up" state of the slow oscillation. Purkinje cell simple spiking is weakly related to the cerebellar and neocortical slow oscillation in a minority of cells. Our results indicate that the cerebellum generates rhythmic network activity that can be recorded as an LFP in the anesthetized animal, which is driven by synchronized oscillations of the neocortex. Furthermore, we show that correlations between neocortical and cerebellar LFPs persist in the awake animal, indicating that neocortical circuits modulate cerebellar neurons in a similar manner in natural behavioral states. Thus, the projection neurons of the neocortex collectively exert a driving and modulatory influence on cerebellar network activity.

\section{Introduction}

The neocortex continuously generates fluctuating patterns of spontaneous activity that underlie network oscillations (Steriade et al., 2001; Buzsaki, 2006). One prominent pattern of neocortical activity in slow-wave sleep and anesthesia is the slow oscillation $(\sim 1 \mathrm{~Hz})$, consisting of epochs of synchronized activity ("up" states) interspersed with network quiescence ("down" states) (Steriade et al., 1993a,b,c; Cowan and Wilson, 1994; SanchezVives and McCormick, 2000). The slow oscillation is generated within the cerebral cortex through activation and deactivation of recurrent cortical networks (Cowan and Wilson 1994; Paré et al., 1998; Shu et al., 2003; Haider et al., 2006). These barrages of synaptic activity strongly depolarize neocortical neurons (by $\sim 15-25 \mathrm{mV}$ ), increase membrane conductance, and fundamentally alter response properties of single neocortical neurons to synaptic inputs both in vivo (Timofeev et al., 1996; Petersen et al., 2003; Sachdev et al., 2004; Haider et al., 2007; Hasenstaub et al., 2007 ) and in vitro (Shu et al., 2003). Because layer 5/6 subcortical projection neurons are activated during up states (Cowan and Wilson, 1994; Contreras and Steriade, 1995; Sanchez-

\footnotetext{
Received May 18, 2009; accepted June 28, 2009.

This work was supported by National Institutes of Health grants and the Kavli Institute for Neuroscience. We thank M. R. Rasin for his help, Ben Micklem for help with graphics, D. Jaeger, Y. Loewenstein, and J. Mazer for helpful discussions, and G. Leydon for technical assistance.

*H.R. and R.N.S.S. contributed equally to this work.

Correspondence should be addressed to either David A. McCormick, Nenad Šestan, or Robert N. S. Sachdev, School of Medicine, Yale University, 333 Cedar Street, SHM I 409, New Haven, CT 06520. E-mail: david.mccormick@ yale.edu, nenad.sestan@yale.edu, or robert.n.s.sachdev@yale.edu.

H. Roš's present address: Department of Neuroscience, Physiology and Pharmacology, University College London, 323 Rockefeller Building, 21 University Street, London WC1E 6DE, UK. E-mail: h.ros@ucl.ac.uk.

DOl:10.1523/JNEUROSCI.2327-09.2009

Copyright $\odot 2009$ Society for Neuroscience 0270-6474/09/2910309-12\$15.00/0
}

Vives and McCormick, 2000), it is expected that subcortical structures would be influenced by slow oscillations. Indeed, recordings of neural activity from thalamus, basal ganglia nuclei, and other subcortical structures indicate strong descending cortical influences during rhythmic cortical activities (Steriade et al., 1993b; Timofeev and Steriade, 1996; Stern et al., 1997; Magill et al., 2000; Haslinger et al., 2006; Mena-Segovia et al., 2008). Given that neocortex exerts a profound effect on these targets, it might be expected that spontaneous activity of cerebellar neurons could be similarly influenced. Previous studies have demonstrated coherent oscillations at higher frequencies $(6-40 \mathrm{~Hz})$ between the local field potential (LFP) of the neocortex and cerebellum in awake behaving animals (Pellerin and Lamarre, 1997; Hartmann and Bower, 1998; Courtemanche et al., 2002; O'Connor et al., 2002; Courtemanche and Lamarre, 2005; Soteropoulos and Baker, 2006; De Zeeuw et al., 2008). However, it is unknown whether spontaneous neocortical activity during slow oscillations entrains activity in cerebellar cortex.

Neocortical efferents could influence cerebellar spontaneous activity by two powerful pathways: via the pons or inferior olive. Pontine neurons give rise to excitatory mossy fibers that synapse with granule and Golgi neurons. Granule cells target Purkinje neurons via excitatory parallel fibers (Ramon y Cajal, 1904; Eccles et al., 1966a,b, 1967; Palay and Chan-Palay, 1974), whereas inferior olive neurons contribute excitatory climbing fiber inputs to Purkinje neurons (Eccles et al., 1966b; Hámori and Szentágothai, 1968; Palay and Chan-Palay, 1974; Walsh et al., 1974).

We examined whether synchronized activity underpinning the slow oscillation in neocortex entrains activity in cerebellar cortex. Through simultaneous single, multiunit (MU), and LFP recordings in cerebellar cortex and neocortex, we demonstrate 
that the cerebellum generates a slow oscillation that is similar to that of the neocortex and that activity of identified granule and Golgi neurons, as well as complex spiking of Purkinje neurons, is entrained by the neocortex. Disrupting neocortical activity abolishes the cerebellar slow oscillation, whereas ablating cerebellar cortex has no overt effect on the neocortical slow oscillation. Furthermore, we show that correlated activity between neocortex and cerebellar cortex persists even in awake animals. The synchronized activity of the neocortex and cerebellar cortex may serve to temporally bind and coordinate the interactions of cortico-cerebellar networks.

\section{Materials and Methods}

Animal surgery. Experiments were performed in accordance with $\mathrm{Na}$ tional Institutes of Health guidelines and were approved by the Yale Institutional Animal Care and Use Committee. Forty-five adult male Sprague Dawley and Long-Evans rats $(250-500 \mathrm{~g})$ were anesthetized with urethane $(1.5 \mathrm{~g} / \mathrm{kg}, 20 \%$ solution; injected i.p.), followed by ketamine and xylazine (75, and $35 \mathrm{mg} / \mathrm{kg}$, i.m.). Anesthesia was supplemented when necessary with ketamine/xylazine. Body temperature was maintained at $37^{\circ} \mathrm{C}$ by a feedback temperature controller. Craniotomies were made over the somatosensory barrel cortex and the cerebellar cortex. The cisterna magna was drained to reduce brain pulsations.

Awake recordings. Adult mice were habituated to handling for 1 week and then surgically prepared for restraint by attaching a head post to the skull and for recording by affixing chambers over cerebellar and neocortical craniotomies, as described previously for rat somatosensory barrel cortex and motor cortex recordings (Sachdev et al., 2000). One week after surgery, animals were restrained by the head post, the chambers were opened, recording electrodes were advanced into the barrel cortex and cerebellar cortex, and MU activity and LFPs were recorded.

Electrophysiological recordings. In anesthetized rats $(n=45)$ and awake mice $(n=5)$, the LFP and MU activity in primary somatosensory barrel cortex and Crus II of the cerebellar cortex was monitored with lowimpedance tungsten microelectrodes $(0.5 \mathrm{M} \Omega$; FHC). The Crus II region of the cerebellar cortex was chosen because it is functionally and anatomically interconnected with the somatosensory barrel cortex (Shambes et al., 1978; Bower et al., 1981; Chen et al., 1996). Extracellular recordings of action potentials of single neurons in cerebellum of the anesthetized animal were made using glass electrodes $(12-30 \mathrm{M} \Omega$; tip diameter, $\sim 1.5$ $\mu \mathrm{m} ; 1.5 \mathrm{~mm}$ glass; World Precision Instruments) pulled on a P-97 horizontal puller (Sutter Instruments) filled with a saline solution $(0.5 \mathrm{M}$ $\mathrm{NaCl}$ ) and Neurobiotin (1.5\%). Electrodes were advanced into the brain, and brain pulsation-related movements were minimized by sealing the craniotomy with low melting point wax. Once data were collected from a stable single unit in the cerebellar cortex, the neuron was labeled using the juxtacellular method (Pinault, 1996) by passing high-intensity current (5-200 nA) pulses, $200 \mathrm{~ms}$ in duration, at $2 \mathrm{~Hz}$ to modulate its firing, as described previously (Wilson and Sachdev, 2004; Mena-Segovia et al., 2008).

Whisker stimulation. Air puffs of 50-250 ms in duration were delivered to multiple whiskers. Unlike the receptive field map for somatosensory barrel cortex, no whisker-by-whisker receptive field map in cerebellum has been established. Thus, the cerebellar multi-whisker receptive fields were established first, and the electrode in neocortex was aligned to the cerebellar receptive field in which at least one of the stimulated whiskers evoked a cortical response. Two stimulus frequencies were used ( 1 or 0.2 $\mathrm{Hz}$ ). Stimulus-triggered LFPs were used as evidence that the cerebellar electrode was in a whisker-responsive zone of cerebellar cortex.

Cell selection. Our criteria were as follows. (1) Single units were labeled juxtacellularly and visualized after stable recordings (minimum of $200 \mathrm{~s}$ ) of spontaneous activity. (2) Cerebellar single-unit recordings of granule and Golgi cells were accepted only if they showed a clear single-unit action potential (meaning a stable action potential waveform with a refractory period of at least $1 \mathrm{~ms}$ ), whereas Purkinje neuron activity was characterized by the presence of complex and fast spiking action potentials. Activity of all cells was always at least twice as large in amplitude versus background activity. (3) Recordings were accepted only when the simultaneously recorded neocortical up and down states could be clearly defined in the LFP trace.

Anatomical and histochemical visualization. Deeply anesthetized animals were perfused with PBS, followed by $4 \%$ paraformaldehyde, and brains were sectioned at $50 \mu \mathrm{m}$ on a vibratome. The identity of labeled neurons was verified using standard histochemical techniques, as described previously (Mena-Segovia et al., 2008), to visualize cells with permanent chromogens for light microscopic analyses. The Neurobiotin was revealed by incubation in cyanine 3-conjugated to streptavidin (1: 1000; Jackson ImmunoResearch). Sections were mounted on slides for viewing with a conventional fluorescence microscope (Leica Microsystems) or a laser-scanning confocal fluorescence microscope (LSM510; Carl Zeiss). Sections were dehydrated and mounted for light microscopy. The somatodendritic and proximal axonal arbors of Neurobiotinlabeled cerebellar neurons were reconstructed from successive serial sections $(50 \mu \mathrm{m})$ using a $63 \times$ objective and digitized using Neurolucida software (MicroBrightField).

Data acquisition. Single-unit electrode signals were acquired with an Axoclamp-2B amplifier (Molecular Devices). MU and LFP data were bandpass filtered (single-unit signals, $500 \mathrm{~Hz}$ to $20 \mathrm{kHz}$; LFP signals, $0.1-100 \mathrm{kHz}$ ) and acquired with an A-M Systems amplifier (model 3000). Electrophysiological data were digitized and analyzed with a personal computer running Spike2 software (Cambridge Electronic Design).

Data analysis. Up state epochs in neocortical MU and LFP recordings were separated from spontaneously occurring down state epochs by setting thresholds. Up states corresponded to periods of higher spike rate in the recorded group of neurons. To determine whether the neocortex was in the up or down state, the LFP trace and the MU trace were aligned, and the MU trace was filtered, rectified, and smoothed to yield an outline of the increases and decreases in activity associated with changes in neocortical state. A lower threshold was placed just above the MU activity or LFP trace for the down state, whereas the upper threshold was placed just below the lower limit of the up state. An up state was initiated when the LFP or MU trace crossed the upper threshold.

Purkinje neurons exhibited one of two distinct patterns of slow oscillatory activity. The majority cycled between epochs of quiescence and a stable spiking rate of $\sim 60 \mathrm{~Hz}(n=8)$ or cycled between periods of firing at $\sim 20-40 \mathrm{~Hz}(n=5)$. To determine whether Purkinje neurons were in a period of higher or lower activity, the firing rate histogram (100 ms bin width) was examined. A lower threshold was placed just above the firing rate for the less active state, and an upper threshold was placed just below the firing rate for the more active state. The more active state was initiated when activity crossed the upper threshold, whereas the less active state occurred when the firing rate of the neuron crossed the lower threshold. We refrain from naming these states up and down (Schonewille et al., 2006), because this terminology is reserved for periods of the neocortical slow oscillation, and the relationship between the bistable discharge of Purkinje cells and the neocortical slow oscillation is unclear.

Complex spikes were distinguished from simple spikes on the basis of the duration and shape of the action potential. Complex spikes were broader, had a complex triphasic shape, and were often larger in amplitude than simple spikes. Complex spikes were identified in each record, and the timing of the spikes was marked; simple spikes were discriminated from background noise on the basis of spike amplitude. The relationship between neocortical up and down states and simple and complex spikes was examined using spike-triggered averages and neocortical up or down state-triggered averages.

Statistical analysis. Data from each recording (100-1000 s) were separated into 10-20 epochs; for each epoch, the mean firing rate and SD during the neocortical up and down states was calculated. For LFP data, the mean correlation and SD were calculated. Significance was assessed for single-neuron data and for averages using paired $t$ tests for each cerebellar single unit and neocortical LFP pair and for each neocortical LFP and cerebellar LFP pair. We assessed the correlation between neocortical and cerebellar LFPs (see Fig. 1) (supplemental Fig. S1, available at www.jneurosci.org as supplemental material) and the correlation between the neocortical slow oscillation and single-unit activity in cerebellar cortex (see Figs. 3-6). 

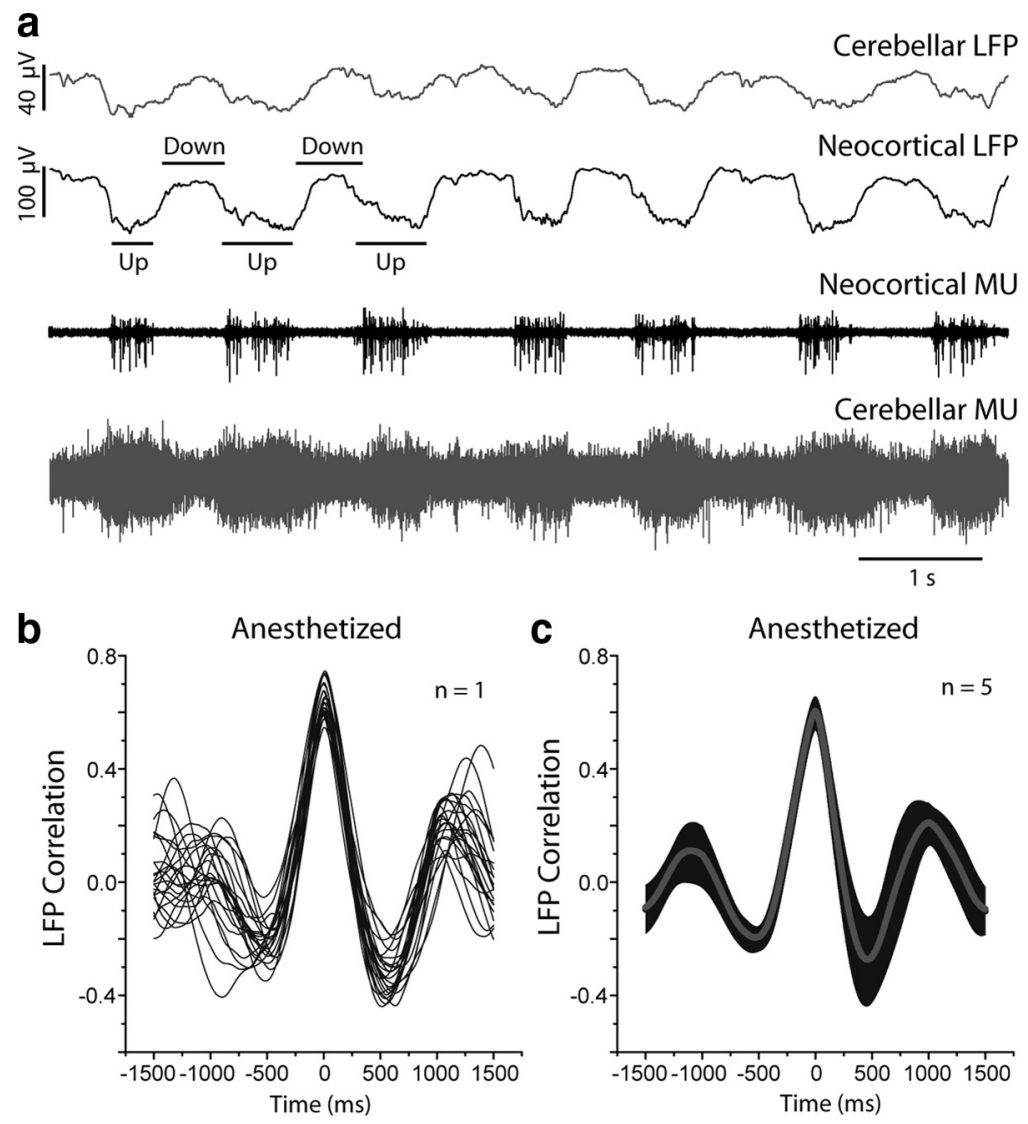

d

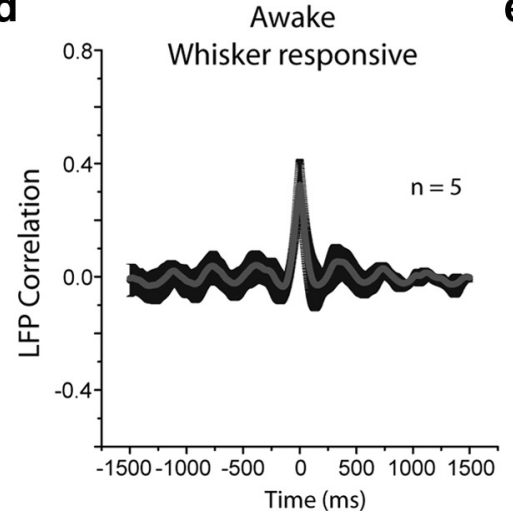

Figure 1. Correlated LFP and MU activity between neocortical and cerebellar networks. $\boldsymbol{a}$, Simultaneous recordings of LFP (top traces) and extracellular MU (bottom traces) reveal rhythmic slow oscillations in both neocortex and cerebellar cortex. Local network activity (up state) is followed by network quiescence (down state). Note that the slow oscillation in the cerebellum is similar to that of the neocortex. $\boldsymbol{b}, \boldsymbol{c}$, Cross-correlation analyses were used to examine the relationship between cerebellar and neocortical LFPs in the anesthetized animal. Data from each experiment was separated into $10-20$ epochs, and the correlation coefficient was calculated, for each epoch $(\boldsymbol{b})$ and the average data $(\boldsymbol{c})$. Note that the mean correlation coefficient was $0.64 \pm 0.06$ $(\boldsymbol{c} ; n=5)$ and that the peak correlation was $0.60 \pm 0.06(\boldsymbol{b} ; n=1) . \boldsymbol{d}, \boldsymbol{e}$, Cross-correlation analyses of cerebellar and neocortical LFPs in the awake animal were calculated for recording sites in which the whisker stimulus evoked an LFP (d) and for those in which it did not (e). The average correlation between whisker-responsive neocortical and cerebellar recording sites was $0.32 \pm 0.10(\boldsymbol{d})$. The average correlation was much lower $(0.18 \pm 0.14)$ between cerebellar Crus II recording sites and whisker-unresponsive recording sites in neocortex (e).

Shuffle correction was used to determine whether the up statetriggered modulation of simple and complex spiking or the complex spiking-triggered simple spiking rates could be explained by rhythmic neocortical up and down states and phasic activity of Purkinje neurons (supplemental Fig. S4, available at www.jneurosci.org as supplemental material). Up state-triggered or complex spike-triggered histograms were prepared from 100 or $200 \mathrm{~s}$ of data. Simple or complex spike times were shuffled (randomized using $1 \mathrm{~s}$ epochs, which were shuffled relative to the triggering event, i.e., up state times, or complex spike-triggered times).

\section{Results \\ Correlated slow oscillations in cerebellar and neocortical networks}

To address whether the neocortical slow oscillation was reflected within cerebellar network activity, we simultaneously recorded MU activity and LFP in both the somatosensory neocortex and Crus II of the cerebellar cortex in ketamine/xylazineanesthetized rats (Fig. 1a). The neocortex generates the slow oscillation during anesthesia, alternating between periods of activity (the up state) and periods of inactivity (the down state). The neocortical up state is characterized by MU activity and a large negative deflection in the LFP. Up states are preceded and followed by down states, which are associated with almost complete silence in the MU recording and a large, positive deflection in the LFP. We show that the simultaneously recorded LFP in cerebellar cortex also exhibits a slow oscillation (Fig. $1 a$, top traces) $(n=5)$ that is similar to that of the neocortex but smaller in amplitude. Just as the neocortical up state LFP is associated with increases in MU activity, the up state of the cerebellar LFP is also associated with increases in cerebellar MU activity (Fig. $1 a$, bottom traces). Importantly, the slow oscillations of the neocortex and Crus II of the cerebellum exhibited strong correlations in their activity. The correlation coefficient between neocortical and cerebellar LFPs in the anesthetized animal (Fig. 1b, single example; $c$, average response; $n=5$ ) ranged between 0.5 and 0.8 (mean, $0.60 \pm 0.06$ ), indicating a strong correlation between the LFPs recorded in cerebellum and neocortex. To ensure that the cerebellar and neocortical recording sites were in functionally related areas, we restricted our recording sites to those that exhibited LFP responses to whisker stimulation (supplemental Fig. S1, available at www.jneurosci. org as supplemental material). However, in the anesthetized animal, alignment is not a critical issue because the entire neocortex, nearly synchronously, generates the slow oscillation (Cowan and Wilson, 1994; Paré et al., 1998; Shu et al., 2003).

Having shown in the anesthetized animal that the cerebellar cortex generates a slow oscillation and LFP that is correlated with that of the neocortex, we next performed simultaneous recordings of neocortical and cerebellar LFPs in the awake animal. Our recordings in awake mice (Fig. $1 d, e)(n=5)$ show that the somatosensory neocortical LFP (supplemental Fig. S1, available at www.jneurosci.org as supplemental material) fluctuated at low frequencies at $2-5 \mathrm{~Hz}$ (Crochet and Petersen, 
2006) and that the cerebellar LFP also exhibited a similar lowfrequency oscillation. Analyses showed that the correlation coefficient between cerebellar and neocortical LFPs (Fig. 1d) ranged between 0.20 and 0.41 (mean, $0.32 \pm 0.10$ ) when the electrodes were aligned to the same receptive field and $0.18 \pm 0.14$ (Fig. 1e) when the electrodes were randomly placed in Crus II of cerebellar cortex. The autocorrelation and power spectra both indicated that a $3-5 \mathrm{~Hz}$ oscillation exists in the cerebellar cortex of the awake animal (supplemental Fig. S1d, available at www.jneurosci.org as supplemental material). Previous work has shown that the frequency of this oscillation is independent of any obvious movement by the animal (Hartmann and Bower, 1998; O'Connor et al., 2002; Dugué et al., 2009). The LFP recordings presented here show that correlated neocortical and cerebellar activity persists even in the awake animal (particularly when electrodes are aligned for whisker-responsive receptive fields). Thus, together, our data demonstrate that, in the absence of any overt external stimulus, neurons in somatosensory barrel cortex and cerebellar cortex fire rhythmically at low frequencies and generate correlated slow oscillations.

To determine whether volume conduction from the visual cortex could contribute to the slow oscillatory activity in cerebellar cortex, electrodes were positioned in layer 5 of visual cortex, and in the ipsilateral rostrolateral cerebellar cortex, at a depth of $\sim 500 \mu \mathrm{m}$. Once MU and LFP data had been collected, the cerebellar electrode was repositioned $\sim 1.5 \mathrm{~mm}$ caudally and the procedure was repeated. The amplitude of the LFP in cerebellar cortex did not change as a function of distance from visual cortex (data not shown). This finding, along with the presence of robust cerebellar MU activity that is correlated with the LFP, suggests that volume conduction alone cannot explain the presence of a slow oscillation in cerebellar cortex.

We next examined whether oscillatory activity in cerebellar cortex was dependent on the neocortical slow oscillation. We induced spreading depression in the neocortex through the local application of potassium acetate (KAc, $3 \mathrm{~m} \mathrm{50-100 \mu l)} \mathrm{on} \mathrm{motor}$ cortex (Magill et al., 2000) while recording the activity of both the neocortex and cerebellar cortex. Spreading depression depolarizes all neuronal elements to $\sim 0 \mathrm{mV}$, resulting in a complete but temporary (10-30 $\mathrm{min}$ ) cessation of neuronal activity (Leao, 1944; Grafstein, 1956). This cessation of activity spreads slowly $(\sim 3-5 \mathrm{~mm} / \mathrm{min}$ ) across the neocortex, once it is initiated (Leao, 1944; Ba et al., 2002). Our results showed that cessation of neuronal activity in the cerebral cortex was associated with a complete block of the slow oscillatory activity as recorded in cerebellar single-unit, MU, and LFP activity (Fig. 2) $(n=3)$, without a block of spontaneous cerebellar unit activity. Recovery of the slow oscillation in the neocortex was associated with recovery of the slow oscillation in the cerebellar LFP and unit activity. These results suggest that the cerebellar slow oscillation, generated through local circuit mechanisms, is driven by the neocortex.

Then, to investigate whether cerebellar activity has any overt influence on the neocortical slow oscillation, we performed a cerebellar ablation, removing the entire cerebellar cortex bilaterally while recording the activity of the somatosensory cortex. The slow oscillations and the MU activity in neocortex had the same frequency distribution before and after the cerebellar ablations (supplemental Fig. S2, available at www.jneurosci.org as supplemental material) $(n=3)$. This experiment revealed that abolition of cerebellar activity had no overt effect on neocortical slow oscillations. As expected from previous work (Steriade et al., 1993; Sanchez-Vives and McCormick, 2000; Shu et al., 2003), these data support the conclusion that the neocortical slow oscillation can be generated intrinsically and is not dependent on input from the periphery or other brain regions.

\section{Activity of cerebellar granule and Golgi neurons is modulated by neocortical network activity}

To identify the cell types responsible for generating the cerebellar MU activity and slow oscillation, we performed extracellular single-unit recordings and labeled individual cerebellar cortical neurons using the juxtacellular method. Neurons were characterized on the basis of their morphological characteristics, including somatodendritic profiles, proximal axonal arbors, somatic position within the molecular, Purkinje, or granule cell layers, as well as their electrophysiological firing patterns (Simpson et al., 2005; Jörntell and Ekerot, 2006; Barmack and Yakhnitsa, 2008). Among the total pool of 26 neurons, we recorded from three specific classes of cerebellar neurons, namely 7 granule, 3 Golgi, and 13 Purkinje neurons.

Granule cells $(n=7)$ were unique in their firing properties in that they generated small $(\sim 2 \mathrm{mV})$ action potentials with a firing rate of $\sim 2-7 \mathrm{~Hz}$, consistent with previously reported in vivo results (Eccles et al., 1971; Hartmann and Bower, 1998; Lu et al., 2005). We found that granule cell spiking was robustly entrained by neocortical network activity: granule cells discharged with clusters of 3-10 action potentials during the up state of the slow oscillation in neocortex and cerebellum (Fig. $3 a$ ). Granule cells fired at a frequency of $1.78 \pm 0.94 \mathrm{~Hz}$ in the down state and significantly increased their spiking to $5.30 \pm 0.98 \mathrm{~Hz}$ (paired $t$ test, $p<0.01$ ) in the up state, an $\sim 300 \%$ change in firing rate (Fig. $3 a, b$ ) (supplemental Video S1, available at www.jneurosci. org as supplemental material). Neocortical up state-triggered histograms, referenced to the up state transition in neocortex, confirmed that a strong correlation existed between granule cell firing and neocortical up states (Fig. $3 b$, single neuron example, left; population average, right). The somata of labeled granule cells (Fig. $3 c$ ) were located in the granule cell layer; their axons ascended into the molecular layer and in two cases could be seen to form a T-shaped parallel fiber (data not shown). Typically, the terminations of the three to four dendrites, extending from the very small somata, exhibited claws at their ends (Fig. $3 c, d$ ), as is typical for cerebellar granule cells (Ramon y Cajal, 1904).

A second population of identified cerebellar neurons that was entrained by the neocortical slow oscillation was also found: Golgi neurons $(n=3)$ fired predominantly during the neocortical up state (Fig. 4). Golgi neurons fired at a frequency of $2.28 \pm$ $1.27 \mathrm{~Hz}$ in the down state and increased their firing to $7.41 \pm 2.26$ $\mathrm{Hz}$ (paired $t$ test, $p<0.01$ ) in the up state, a 326\% change in firing rate (Fig. $4 a, b$ ) (supplemental Video S2, available at www. jneurosci.org as supplemental material). Spike-triggered histograms related to neocortical up and down state transitions confirmed that Golgi spiking occurred predominantly during the neocortical up state (Fig. 4b, single neuron example, left; average, right). Golgi cell somata were located between the Purkinje and granule cell layers; their axons branched extensively and gave rise to numerous boutons in the granule cell layer (Fig. 4c).

\section{Relationship between Purkinje neuron firing and the neocortical slow oscillation}

Purkinje neurons $(n=13)$ fired in the range of $20-60 \mathrm{~Hz}$ (Fig. 5). Two patterns of activity were observed: tonic $(n=4)$ (Fig. $5 a)$ and phasic $(n=9)$ (Fig. $5 b)$. The phasic pattern of activity consisted of long epochs of simple spiking activity, followed by quiescence. This pattern was consistent with the bistable pattern of Purkinje cell activity reported in previous studies (Granit and 
a Neocortical and Cerebellar LFP and MU are in phase

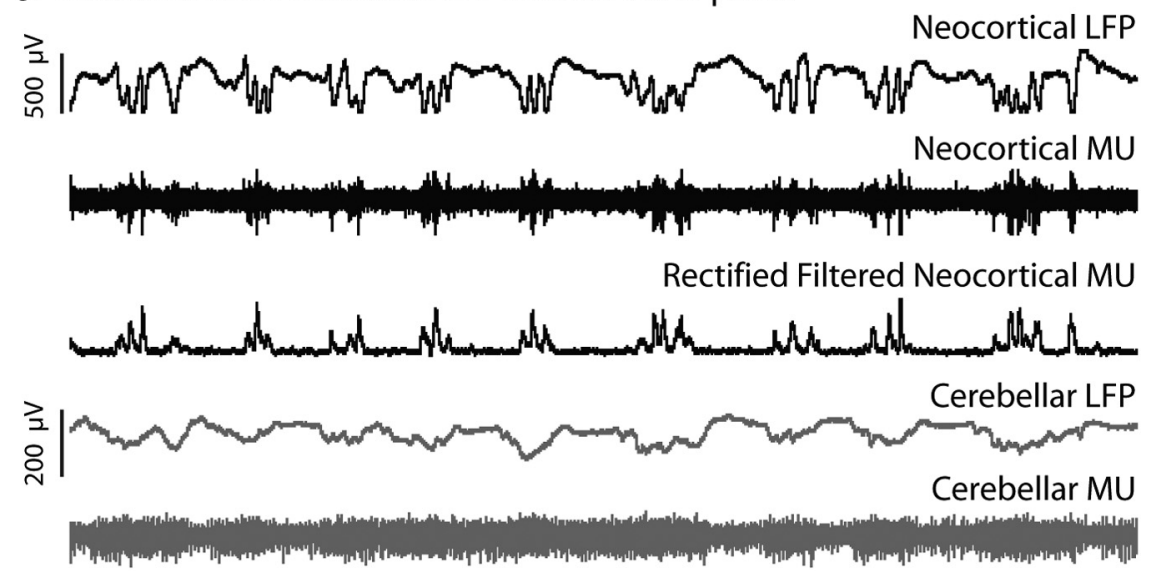

Rectified Filtered Cerebellar MU

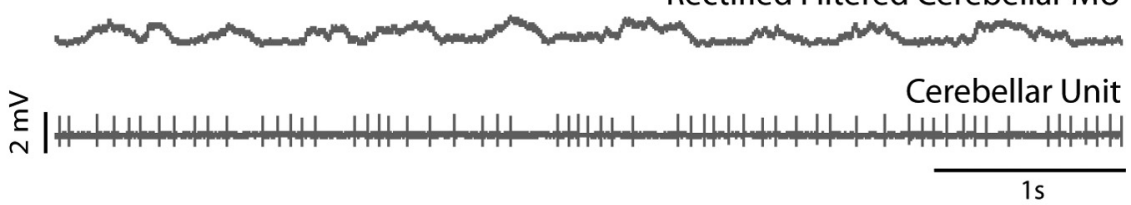

b Spreading Depression in Neocortex Disrupts Cerebellar LFP

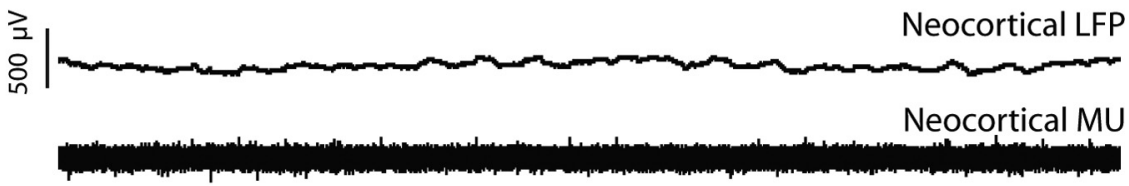

Rectified Filtered Neocortical MU

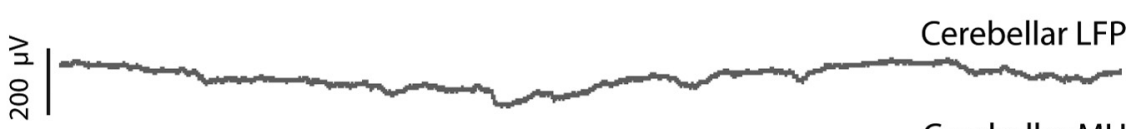

Cerebellar MU

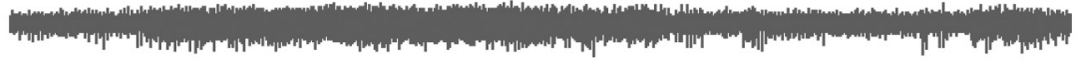

Rectified Filtered Cerebellar MU

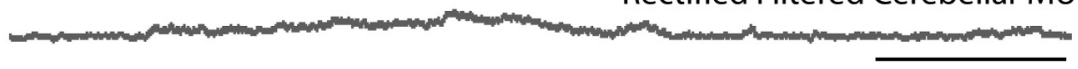

1s

C Recovery of Neocortical and Cerebellar LFP

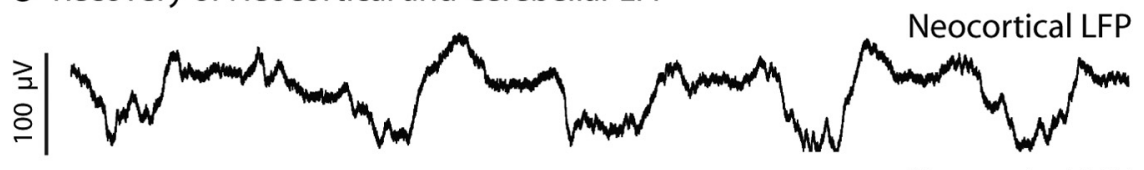

Neocortical MU

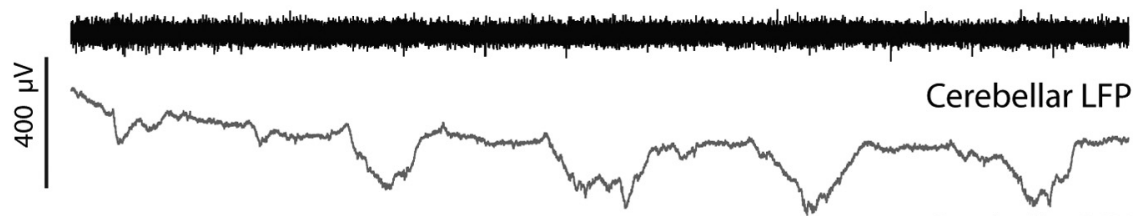

Cerebellar MU

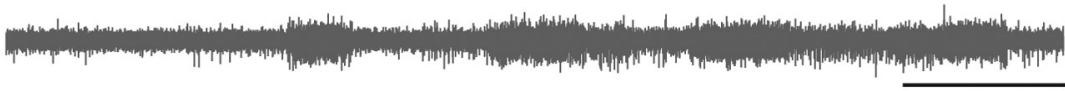

1s

Figure 2. Spreading depression in neocortexabolishes the slow oscillation in cerebellum. $\boldsymbol{a}$, Raw traces of spontaneous activity in neocortex and cerebellum shows the presence of a slow oscillation. $\boldsymbol{b}$, Five minutes after application of potassium acetate $(3 \mathrm{~m} ; 50-100 \mu l)$ locally on neocortex, spontaneous activity ceased in neocortex and the slow-wave oscillation in the LFP was abolished in both neocortex and cerebellum. Note that the cerebellar MU recording continued even after neocortical activity was silenced.c. After recovery, the slow-wave oscillation in the LFP returned to both theneocortex and cerebellum. Local neocortical MU activity does not recover at the site of the potassium acetate application, although it does recover at locations $>1 \mathrm{~mm}$ from the site of application (data not shown).
Phillips, 1956; Bell and Grimm, 1969; Loewenstein et al., 2005; McKay et al., 2007). The tonic pattern of activity, also reported in other previous studies (Armstrong and Rawson, 1979; Armstrong et al., 1979) was not monotonic but also exhibited increases and decreases in activity (11 of 13 cells), which often appeared to have a periodicity of $\sim 0.5-2 \mathrm{~Hz}$ (Fig. $5 a$ ).

To correlate Purkinje cell spiking with ongoing neocortical slow oscillations, we analyzed up state-triggered averages of simple spikes and complex spikes with neocortical up and down states (Fig. $5 c$ ). The majority ( 9 of 13) of Purkinje neurons showed no up state-related modulation in simple spiking activity (Fig. $5 c$, middle): neurons fired simple spikes independently of neocortical up and down states, with an average firing rate of $31.0 \pm 1.0 \mathrm{~Hz}$ in the down state and an average firing rate of $31.8 \pm 0.9 \mathrm{~Hz}$ in the up state (Fig. $5 c$ ). To examine whether Purkinje neurons showed a statistically significant relationship to the up and down states, the data from each neuron was divided into 10-20 epochs, and the correlation between firing rates (binned and low-pass filtered) and neocortical up and down states was assessed. A fraction of Purkinje neurons $(n=4)$ exhibited spontaneous activity that was significantly correlated with neocortical up states: these cells increased their simple spiking rate from an average of $22.5 \pm 2.6 \mathrm{~Hz}$ in the down state, to $32.0 \pm 3.8 \mathrm{~Hz}$ in the up state (Fig. $5 c$, right). The firing rate of these cells showed a clear correlation with neocortical slow oscillations in all 10-20 epochs. In contrast, the activity of the majority of neurons $(n=9)$ was negligibly correlated with the neocortical LFP (Fig. 5c) (supplementalFig. S3, availableatwww. jneurosci.org as supplemental material). Thus, across the average of all Purkinje neurons $(n=13)$, neocortical up states caused an overall $11 \%$ increase in simple spike firing rates $(29.8 \pm 1.2 \mathrm{~Hz}$ in down to $32.9 \pm 1.3 \mathrm{~Hz}$ in up; paired $t$ test, $p<$ 0.01) (Fig. $5 c$, left). To examine whether the up state-triggered simple spike histograms resulted from phasic activity of Purkinje neurons, the neocortical up state timing was shuffled relative to Purkinje cell activity. Shuffling abolished the relationship between the up states and simple spikes, suggesting that the spontaneous activity pattern of Purkinje neurons cannot explain the up state-triggered histograms of simple spiking $(n=4)$ (supplemental Fig. S4, available at www. jneurosci.org as supplemental material). Purkinje neurons had dendrites that ar- 

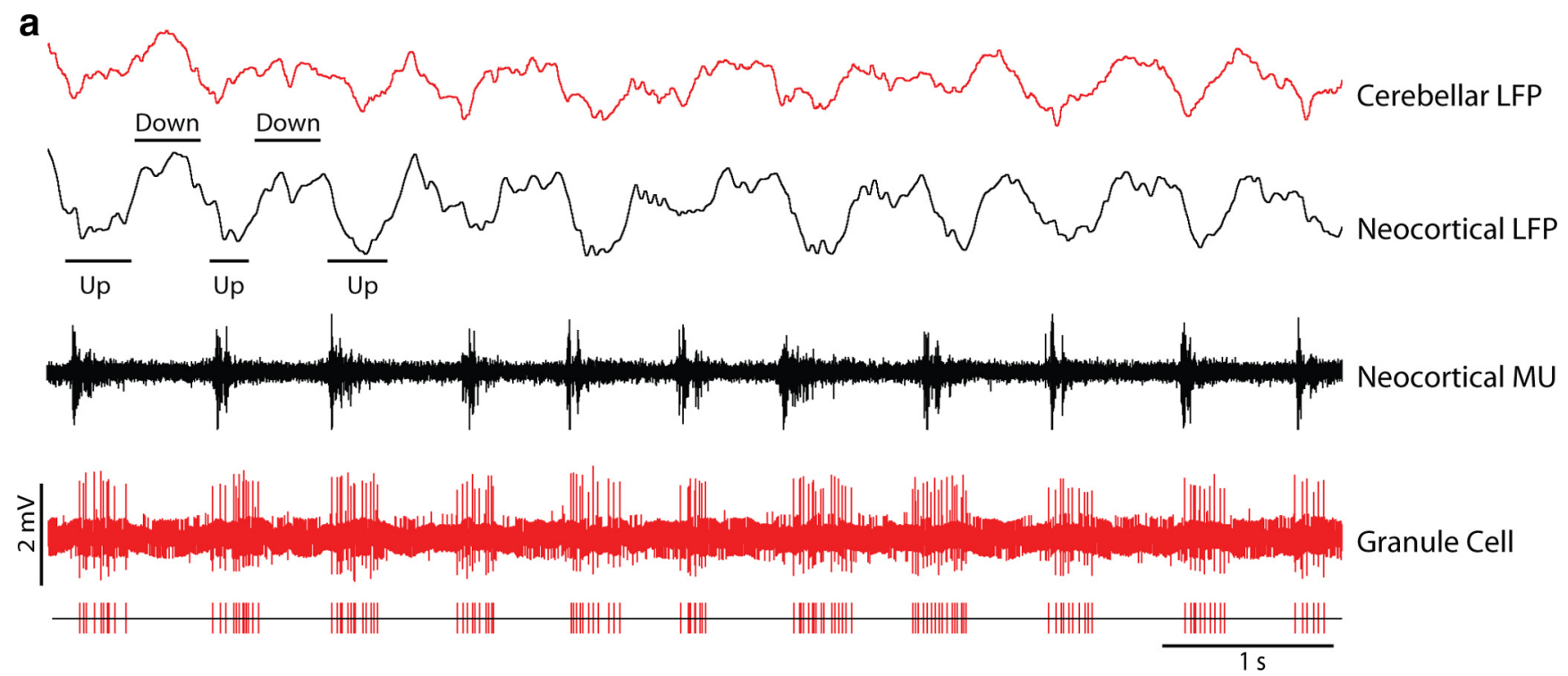

Granule Cell

b

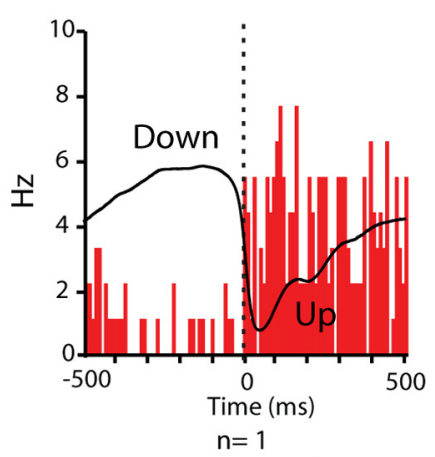

C

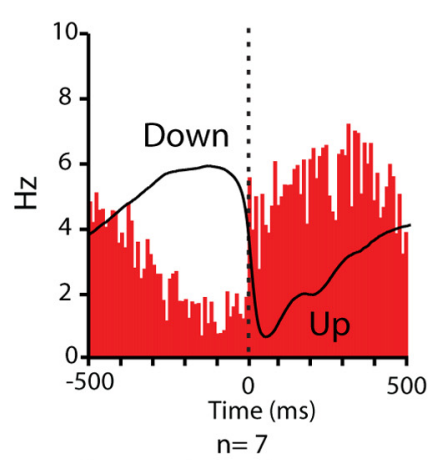

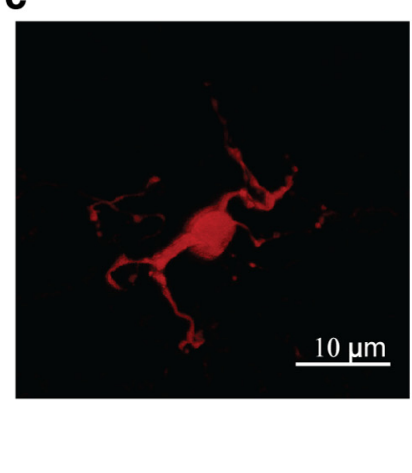

d

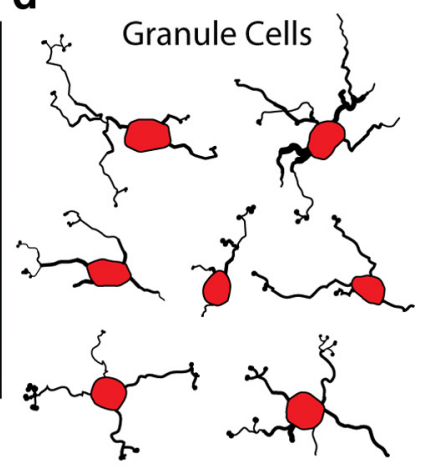

Neocortical Up-triggered Granule Spiking

Figure 3. Neocortical up states entrain activity of granule cells in cerebellar cortex. $\boldsymbol{a}$, Raw trace of spontaneous activity of a granule cell in vivo during ongoing neocortical and cerebellar slow oscillatory activity. Granule cell spiking is intimately related to the up state of the neocortical slow oscillation. $\boldsymbol{b}$, Granule cell discharge of a single neuron (left) and the population mean (right; $n=$ 7) are tightly related to the slow oscillation of the average neocortical LFP (overlaid in black), showing that these neurons predominantly fire during the neocortical up state. Spontaneous activity of granule cells is shown relative to the neocortical up state onset (time 0 in both up-triggered histograms; red). Bin size is 10 ms. $c$, Confocal fluorescence micrograph of the recorded and labeled granule cell ( $\boldsymbol{a}$, above). The four primary dendrites gave rise to claw endings, typical of granule cells. $\boldsymbol{d}$, Neurolucida reconstructions of all juxtacellularly labeled granule cells ( $n=7$ ).

borized profusely in the manner typical for Purkinje cells and a ventrally emerging axon that formed a V-shaped recurrent axon collateral, which presumably formed synapses onto other adjacent Purkinje neurons (Fig. 5d) (Ramon y Cajal, 1904; Palay and ChanPalay, 1974).

In contrast to the minimal effect of neocortical activity on simple spike discharge, the neocortex robustly modulated complex spiking in all Purkinje neurons (Fig. 6) $(n=13)$. Purkinje neurons predominantly generated complex spikes during the neocortical up state (Fig. 6a, complex spike expanded below). Neocortical up state-triggered histograms of complex spiking (Fig. $6 b$ ) exhibited an increase in complex spiking during the neocortical up state (Fig. $6 c$, single cell, left; average, right). Average firing rates ( $n=13$ neurons) for complex spikes were $0.65 \pm 0.23 \mathrm{~Hz}$ in the up state and $0.24 \pm 0.16 \mathrm{~Hz}$ in the down state, reflecting a significant increase of $270 \%$ (paired $t$ test, $p<0.01$ ).

Previous investigations have suggested that the occurrence of complex spikes can trigger transitions between active or silent periods of simple spike activity in cerebellar Purkinje cells (Loewenstein et al., 2005; Fernandez et al., 2007; McKay et al., 2007). To examine this possibility in our recordings, we analyzed complex spike-triggered histograms of simple spiking. We ob- served a broad distribution of single spikes around the occurrence of complex spikes (Fig. $6 c$ ). This broad distribution had two clear aspects: first, $\sim 50-100 \mathrm{~ms}$ after the incidence of complex spikes, simple spikes are rare or reduced in occurrence (Fig. 6c), as reported previously (a "pause" in simple spiking) (Granit and Phillips, 1956; Thach, 1967; Bell and Grimm, 1969; Bloedel and Roberts, 1971). Second, outside of such pauses, simple spike activity exhibited gradual increases and decreases leading up to, and after, the occurrence of complex spikes (Fig. $6 c$ ). In contrast to previous results (Loewenstein et al., 2005; Fernandez et al., 2007; McKay et al., 2007; Yartsev et al., 2009), in the large majority of our recorded cells $(n=11$ of 13$)$, complex spikes were not followed by sudden transitions in simple spike activity triggered by complex spikes. In only 2 of 13 neurons were complex spikes, followed by a transition to increased simple spiking (data not shown) (Loewenstein et al., 2005; Fernandez et al., 2007; McKay et al., 2007).

We have seen from MU and LFP recordings that the neocortex and cerebellum exhibit transitions between active and inactive periods as characterized by the slow oscillation. Similarly, Purkinje neuron single-spike activity also exhibits periods of increased and decreased activity that has a periodicity similar to 


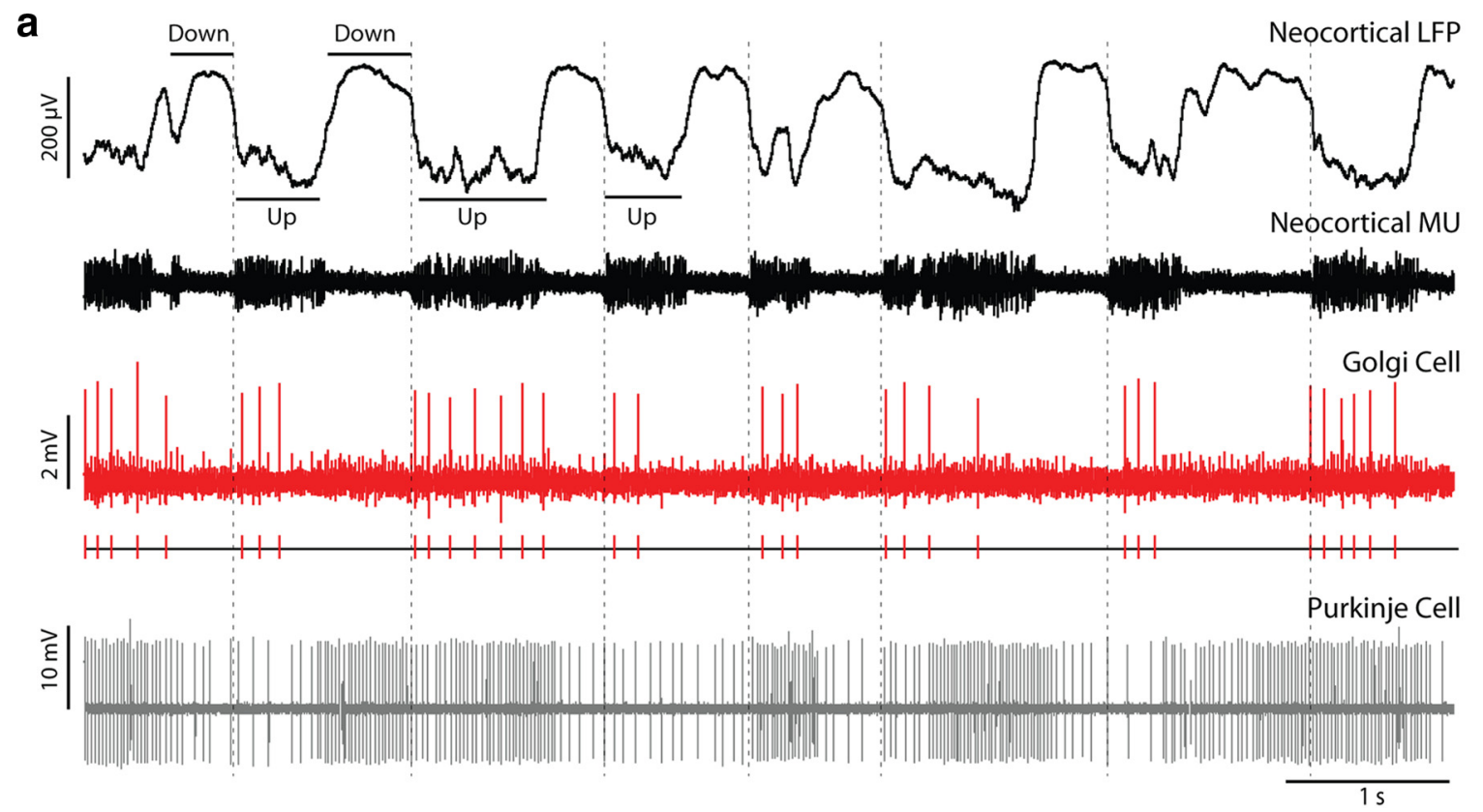

b

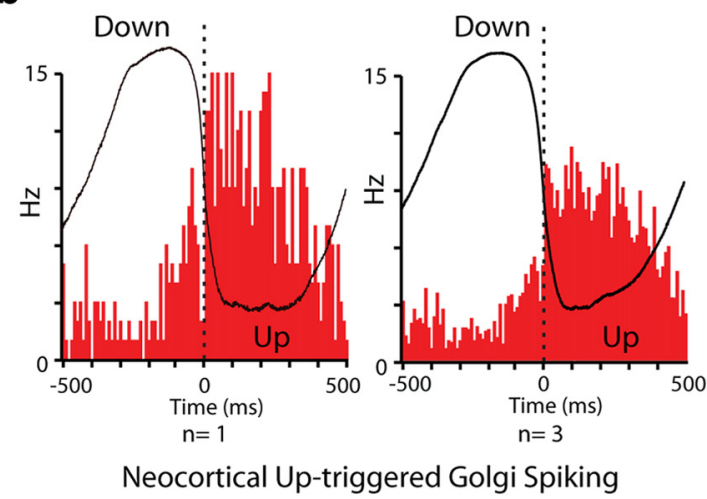

C

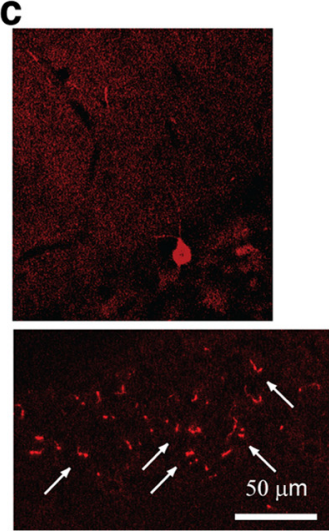

d

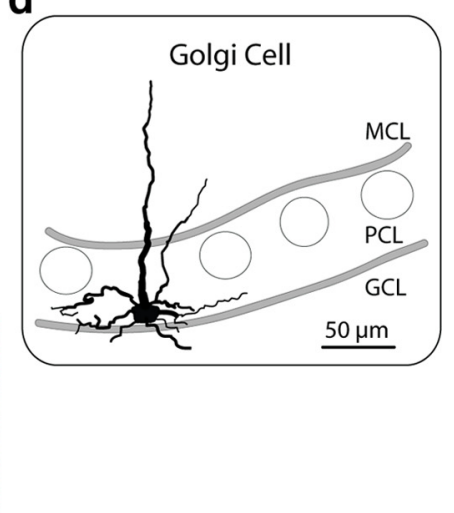

Figure 4. Activity of cerebellar Golgi neurons is increased during neocortical up states. $\boldsymbol{a}$, Raw trace of spontaneous activity of a Golgi cell and a Purkinje neuron in vivo during ongoing neocortical network activity. The discharge of the Golgi cell, but not the Purkinje neuron, faithfully occurs during the up states of the neocortical slow oscillation. $\boldsymbol{b}$, Spike discharge of a single Golgi neuron (left) and the population mean (right; $n=3$ ) are related to the average slow oscillation of the neocortical LFP (overlaid in black), showing that these neurons predominantly fire during the neocortical up state. Spontaneous activity of Golgi neurons is shown relative to the neocortical up state onset (time 0 in both up-triggered histograms; red). Bin size is $10 \mathrm{~ms}$. $\boldsymbol{c}, \boldsymbol{d}$, Confocal fluorescence micrograph $(\boldsymbol{c})$ and reconstruction $(\boldsymbol{d})$ of the recorded and labeled Golgi neuron. The long dendrites (black) extended into the molecular cell layer (MCL) and Purkinje cell layer (PCL); the axon gave rise to a dense local axon network, studded with numerous varicosities (c, bottom, white arrows) within the underlying granule cell layer (GCL).

that of the slow oscillation. To examine whether neocortical up states were correlated with these transitions in Purkinje cell activity, we first identified the timing of each Purkinje cell transition in phasically active neurons, in which the transition between active and inactive epochs was clear. Examining the distribution of the timing of these transitions in Purkinje cell firing rate in relation to the onset of neocortical up states revealed no statistically significant relationship between the two (paired $t$ test, $p>$ 0.1 ) (Fig. 6d).

In summary, we found that both granule and Golgi neuron firing was intimately related to neocortical up states, thereby implicating cortico-pontine synaptic input to these cells as a likely generator of the oscillatory cerebellar MU activity. In contrast, most Purkinje neurons do not exhibit a phase preference for the neocortical up or down state in their simple spike firing discharge yet are tightly coupled to the neocortical up state in their complex spike firing.

\section{Discussion}

Do cerebellar circuits generate synchronized slow oscillations? Does the neocortex pace cerebellar activity? The results presented here demonstrate that slow network oscillations impose spatially and temporally coherent activity both within and between the neocortex and cerebellar cortex. Neocortical output entrains and drives cerebellar network activity and generates a cerebellar LFP and electroencephalogram (EEG) that is similar to that of the neocortex, which results in part through the activation of granule, Golgi, and Purkinje neurons.

Correlated cerebellar and neocortical network oscillations Our recordings of LFP and MU activity demonstrate that the cerebellar cortex generates a slow oscillation that is dependent on the neocortex for its expression and that slow oscillations in both neocortical and cerebellar networks are strongly correlated. The neocortical slow oscillation occurs naturally during slow-wave 
a Tonic Purkinje

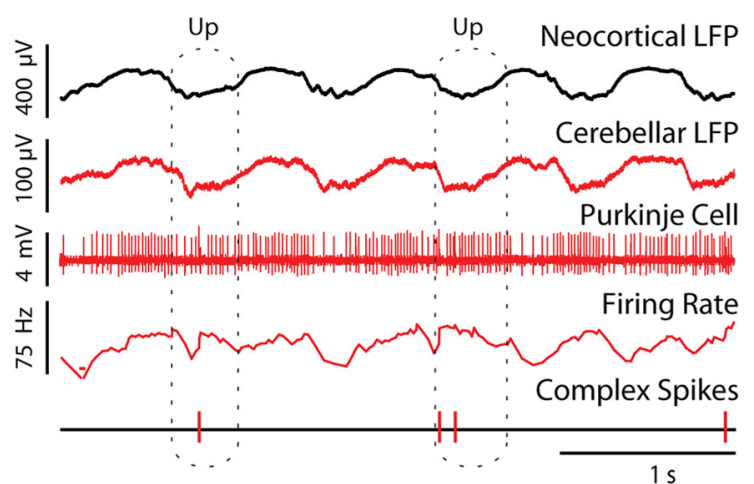

b Phasic Purkinje

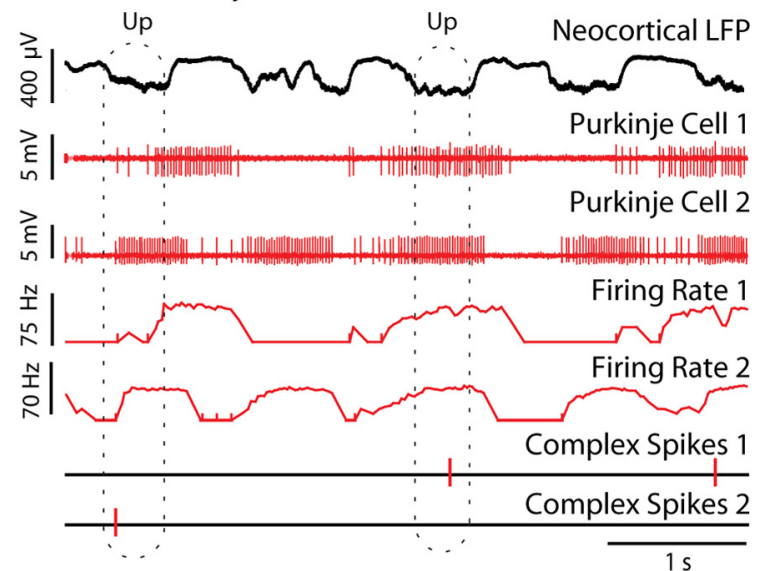

C

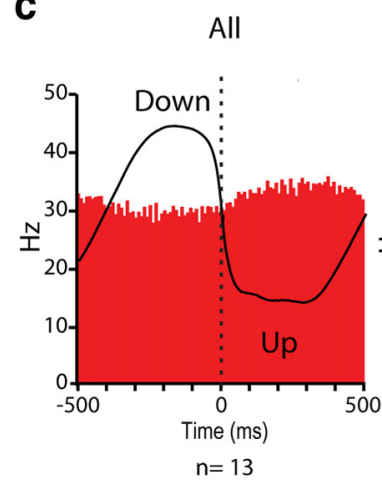

CtxUp-state Non-related

CtxUp-state Related

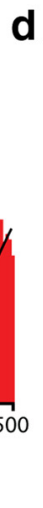

\section{d}

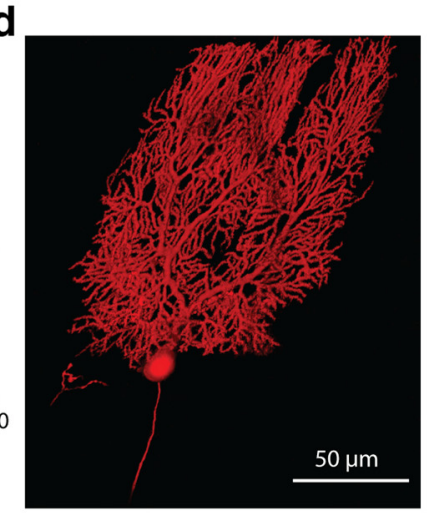

Neocortical Up-triggered Purkinje Simple Spiking

Figure 5. Simple spiking in cerebellar Purkinje neurons is weakly related to the neocortical slow oscillation. $\boldsymbol{a}$, Simultaneous LFP recordings (top 2 traces) reveal rhythmic slow oscillations in both neocortex (black) and cerebellar cortex (red). Raw trace of spontaneous activity of a tonically firing Purkinje cell during ongoing, neocortical and cerebellar network activity shows no clear relationship to slow network oscillations. $\boldsymbol{b}$, Raw traces of spontaneous activity of two simultaneously recorded phasic Purkinje cells during neocortical activity shows a weak relationship to slow network oscillations. Note that simple spiking firing rate (red traces, averaged over $100 \mathrm{~ms}$ ) is not related to up and down states, whereas complex spikes in both $\boldsymbol{a}$ and $\boldsymbol{b}$ are generated during the neocortical up state (dashed boxes). $c$, Average data for firing patterns of all Purkinje neurons ( $n=13$; left), neurons that were not modulated ( $n=9$; middle) and neurons that were modulated $(n=4$; right) in relation to the neocortical slow oscillation. Note that the firing pattern distributions for Purkinje neurons are similar during neocortical up and down states. Spontaneous simple spiking of Purkinje neurons is shown relative to the neocortical up state onset (time 0 in all up-triggered histograms; red) and the average neocortical LFP (overlaid in black). Bin size is $10 \mathrm{~ms}$. $\boldsymbol{d}$, Confocal fluorescence micrograph of a recorded and labeled Purkinje neuron. The dendrites arborized profusely, and the axon gave rise to a local recurrent axon collateral with varicosities.

sleep and is strongly promoted by certain anesthetics, such as ketamine/xylazine, which was used in the present study (Steriade et al., 1993, 2001; Timofeev et al., 2001). Slow, rhythmic oscillations in neocortical activity have also been observed in the waking state, especially during periods of inattentiveness (Crochet et al., 2006; Ferezou et al., 2006). Previous studies have reported cerebellar oscillations (De Zeeuw et al., 2008) at frequencies between 6 and $40 \mathrm{~Hz}$ (Pellerin and Lamarre, 1997; Hartmann and Bower, 1998; Courtemanche et al., 2002; O'Connor et al., 2002; Courtemanche and Lamarre, 2005) and have demonstrated that the cerebellar cortex is able to generate very fast oscillations in the gamma range and higher $(40-200 \mathrm{~Hz})$ (de Solages et al., 2008; Middleton et al., 2008). Furthermore, excitatory and inhibitory feedback loops between granule and Golgi cells potentially subserve some of the fast LFP oscillations and intrinsic rhythmogenesis of cerebellar cortex (Dieudonne, 1998; Maex and De Schutter, 1998; Courtemanche et al., 2002). Previous work has also shown that motor and somatosensory cortices and cerebellum show coherent oscillatory LFP patterns in the $10-25 \mathrm{~Hz}$ beta range in awake rats (O'Connor et al., 2002), and behaving monkeys (Pellerin and Lamarre, 1997; Courtemanche et al., 2002), and that coherence between neocortex and cerebellum can be modulated with the attentional state of the animal (O'Connor et al., 2002; Courtemanche and Lamarre, 2005; Soteropoulos and Baker, 2006; Witham and Baker, 2007). Taken together, previous work indicates that cerebellar circuitry can independently generate oscillatory activity but that neocortical and cerebellar EEGs also show similar oscillations generated by either common subcortical or peripheral inputs to neocortex and cerebellum or by cortico-cerebellar loops and connections.

The present study shows that the slow oscillation occurs in both the neocortex and cerebellar cortex. Importantly, we found that specific subpopulations of neurons contribute to the cerebellar oscillation and that the slow oscillatory activity of the cerebellum is dependent on that of the neocortex for its expression. In awake animals, we also observed coherent neocortical-cerebellar field potential activity at relatively low frequencies, supporting previous results that neocortical-cerebellar communication and coordination may be important in generation and synchronization of $6-8 \mathrm{~Hz}$ oscillations in cerebellar cortex of awake rats (Hartmann and Bower, 1998; O'Connor et al., 2003) and the $3-5 \mathrm{~Hz}$ oscillation seen in the neocortex of awake mice (Crochet and Petersen, 2006) (supplemental Fig. S1, available at www.jneurosci.org as supplemental material). Furthermore, as has been shown recently, even in the awake animal, 
a
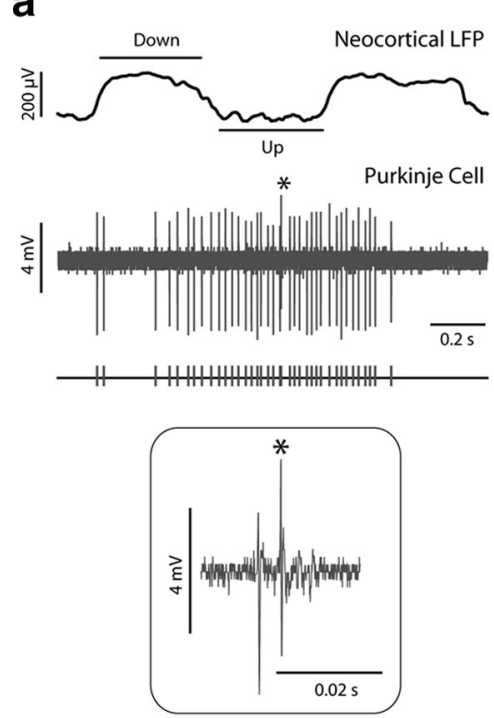

b

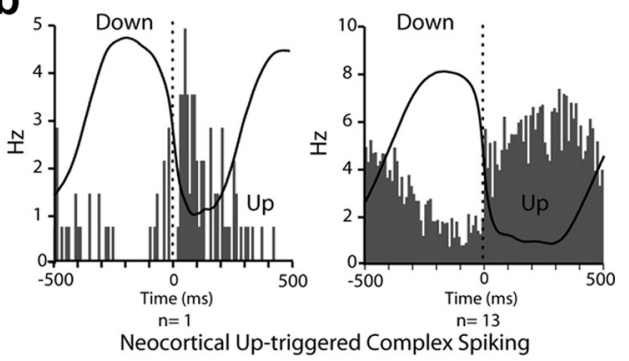

C

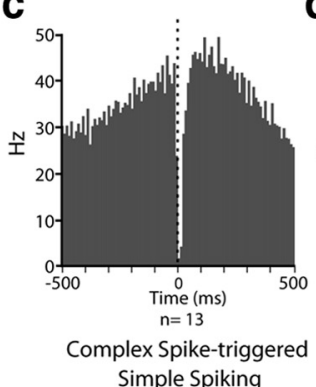

d

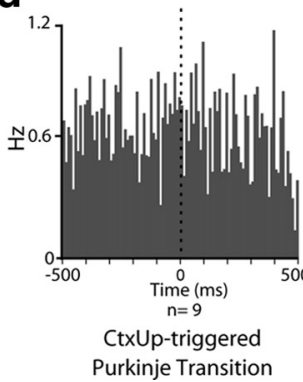

Figure 6. Complex spikes in cerebellar Purkinje neurons are generated during neocortical up states. $\boldsymbol{a}$, Raw traces of spontaneous activity of a Purkinje cell during ongoing neocortical activity shows that the complex spike (asterisk, expanded below) is generated during the neocortical up state. $\boldsymbol{b}$, Average data for complex spike firing of one Purkinje neuron (left) and all Purkinje neurons ( $n=13$; right) related to the neocortical slow oscillation. Note that the occurrence of complex spikes is modulated by neocortical network activity. Spontaneous complex spiking of Purkinje neurons is shown relative to the neocortical up state onset (time 0 in both up-triggered histograms; red) and the average neocortical LFP (overlaid in black). c, Complex spike-triggered histogram of simple spikes shows that complex spikes do not toggle Purkinje cell simple spiking from periods of high to low activity. Note that complex spikes produce a brief pause $(50-75 \mathrm{~ms}$ ) in simple spiking at time 0 . $\boldsymbol{d}$, Neocortical up-triggered histogram of Purkinje state transitions in phasically active Purkinje neurons. The time of transition from a period of lower to higher rates of action potential activity were identified and plotted in relation to the onset of the up state in the neocortex (time 0). Note that no consistent relationship is seen between the slow oscillation and the onset of increased discharge in Purkinje cells. Bin size is $10 \mathrm{~ms}$.

Golgi neuron activity is correlated with low-frequency $(<10 \mathrm{~Hz})$ oscillations in the cerebellar cortex (Dugué et al., 2009).

\section{Neocortical network activity entrains cerebellar granule and Golgi neurons}

The up state of the neocortical slow oscillation is produced by balanced recurrent activity in inhibitory and excitatory circuits in neocortex. This phasic activity, which occurs in all or most neocortical areas, is transmitted to thalamus, striatum, and other subcortical nuclei (Steriade et al., 1993b; Contreras and Steriade, 1995; Wilson and Kawaguchi, 1996; Stern et al., 1997; Haslinger et al., 2006; Mena-Segovia et al., 2008). The slow rhythmic activity in cerebellar cortex appears to be generated by interactions between distinct classes of cerebellar neurons, driven by neocortical activity. Our results indicate that activity in neocortical up states is also transmitted to cerebellar cortex via pontine nuclei and inferior olive. The cortico-pontine pathway might promote oscillations robustly because population discharge of pyramidal tract neurons faithfully transmits neocortical oscillations (Baker et al., 2003). Similarly, projections from cerebral cortex to inferior olive, mediated by the mesodiencephalic junction (for review, see De Zeeuw et al., 1998), can entrain neurons in the inferior olive (Brown and Bower, 2002; Marshall and Lang, 2004). Our observation of up state-triggered Purkinje complex spikes, which result from activation of climbing fiber inputs from the inferior olive, supports this hypothesis.

Mossy fibers from pontine nuclei target cerebellar granule and Golgi neurons. Sensory-evoked activation of cortico-pontine mossy fibers has been shown previously to generate synaptic and spiking responses within the cerebellar granule cell layer (Morissette and Bower, 1996; Chadderton et al., 2004; Jörntell and Ekerot, 2006; Rancz et al., 2007). Consequently, neocortical spontaneous activity should modulate activity of both granule and Golgi neurons. Our results indicate that neocortical activity is indeed transmitted to both cell types, resulting in simultaneous activation of at least some proportion of excitatory and inhibitory neurons in cerebellar circuits. Golgi neurons are also activated by parallel fibers from granule neurons and provide feedback inhibition. The activation of Golgi cells may limit the firing rate of active granule cells or even cause them to remain silent (Chadderton et al., 2004; Dugué et al., 2009).

Previous theoretical considerations suggest that activity in mossy fibers can entrain granule and Golgi neurons to oscillate at frequencies between 10 and $40 \mathrm{~Hz}$ (Maex and De Schutter, 1998). Here we show that both Golgi and granule neurons are also entrained at the slow oscillation frequency and that both classes of neurons are indeed activated in the up state of the neocortex. One consequence of this activation is that it leads to the slow oscillation-related MU activity recorded in the cerebellar cortex. The activation of both excitatory and inhibitory neurons in the cerebellar cortex suggest that there may be a relative balance of inhibitory and excitatory synaptic potentials in neurons postsynaptic to both of these influences (e.g., granule cells), as occurs in neocortical pyramidal cells during the up state of the slow oscillation (Shu et al., 2003; Haider et al., 2006). However, this may not necessarily be the case because, in the cerebral cortex, the balance is achieved through massive recurrent excitatory and inhibitory interconnections (LeVay and Gilbert, 1976; Peters and Payne, 1993; Douglas et al., 1995), which are essentially absent in the cerebellum.

\section{Neocortical slow oscillation and Purkinje activity}

Neocortical activity can modulate the discharge of Purkinje neurons via two pathways: (1) the parallel fiber pathway, mediated by mossy fiber projections to granule and Golgi neurons, or (2) the climbing fiber pathway, from motor cortex to the inferior olive. Our results show that the occurrence of neocortical up states and complex spikes are well coordinated: complex spiking activity is more likely when neocortical circuits are in the up state. Complex spiking is critical in that it produces a strong depolarization of Purkinje cell dendrites (Llinás et al., 1968; Llinás and Sugimori, 1980) along with a pause (Granit and Phillips, 1956; Thach, 1967; Bell and Grimm, 1969; Bloedel and Roberts, 1971) in simple spiking for $\sim 50$ $100 \mathrm{~ms}$, and causes strong inhibition followed by rebound excitation in the deep cerebellar nuclei (Aizenman and Linden, 1999). Our finding that neocortical activity entrains complex spiking in Purkinje neurons (Provini et al., 1968; Brown and Bower, 2002; Marshall and Lang, 2004) reinforces the longheld hypothesis that this long-distance connection participates in 
coordinating activity between neocortex and cerebellum (Marr, 1969; Albus, 1971; Ito, 1984; Hurlock et al., 2008; Medina and Lisberger, 2008).

One interesting observation that remains to be explained is that, unlike complex spiking, Purkinje simple spiking is only weakly modulated by neocortical activity. Previous studies have shown that single spiking in Purkinje neurons occurs in the absence of synaptic input (Häusser and Clark, 1997) and is generated through intrinsic membrane mechanisms, primarily through the presence of a resurgent or persistent $\mathrm{Na}^{+}$current (Raman and Bean, 1997; Khaliq et al., 2003). There are numerous possible reasons for a lack of strong modulation of Purkinje cell firing rate by the neocortical slow oscillation. Because we found that the average population activity of granule cells is strongly influenced by the up state of the neocortex and it is known that $>150,000$ granule cells may contact each Purkinje neuron, our results suggest that the influence of each granule cell is weak (Eccles et al., 1967; Palkovits et al., 1972; Napper and Harvey, 1988). Furthermore, parallel fiber inputs to Purkinje cells are located distally on their dendritic arbors (Palkovits et al., 1972; Palay and ChanPalay, 1974), and individually these may be relatively ineffective in driving Purkinje cell activity (Isope and Barbour, 2002). Another possibility is that granule cell activity needs to be synchronized over smaller time windows to be effective in modulating the intrinsic and ongoing firing of Purkinje cells and that such tight synchrony is not achieved during spontaneous up states. In addition, although all granule cells that we recorded were strongly modulated by up state activity, it is unknown whether this is representative of granule cell activity across the entire network. Extracellular recordings are biased toward active neurons, and it is possible that many granule cells may be silent during up and down states. Our recordings showing robust MU activity during up states suggest that it is unlikely that we missed a large population of silent granule cells in our recordings.

An additional possible reason for a lack of modulation of Purkinje cell activity by granule cell discharge during up states is that the activation of local interneurons, such as stellate (Jörntell and Ekerot, 2002) or basket cells, which target dendritic and somatic regions of Purkinje cells, prevent the dendritic depolarizations generated by parallel fiber inputs from affecting action potential initiation in Purkinje cell axons (Eccles et al., 1966b,c,d, 1967; Jaeger et al., 1997; Jaeger, 2003; Santamaria et al., 2007). Pharmacologically reducing GABAergic inhibition in the molecular layer of cerebellar cortex not only results in large increases in Purkinje cell simple spike responses to peripheral somatic stimulation but also allows previously unresponsive cells to become responsive (Santamaria et al., 2007). Computational models suggest that this gating function of inhibition may arise from the activation of molecular layer inhibitory interneurons that control the flow of excitatory synaptic activity through the Purkinje cell dendritic arbor (Santamaria et al., 2007). Finally, intrinsic mechanisms, or indeed anesthesiarelated effects (Bengtsson and Jörntell, 2007) that block the influence of granule cells on simple spiking in Purkinje cells, may also have contributed to the lack of observed modulation of Purkinje cell simple spike activity in relation to neocortical activity. Whatever the mechanism, the observation that large increases in activity of neocortical neurons in the transition from down to up states can have relatively mild effects on Purkinje cell simple spiking indicates that important, and as of yet unknown, processes occur that regulate the coupling of neocortical and cerebellar cortical activities.

\section{Functional implications of cortico-cerebellar interactions}

We show that the cerebellar EEG is generated by interactions of networks of distinct classes of cerebellar neurons and is driven by network activity in neocortex. The observed oscillations may serve to functionally link large ensembles of neurons within local cerebellar circuits and neocortical neuronal populations. Thus, although neocortex and cerebellum share the ability to generate correlated slow oscillations, the mechanisms and neuronal interactions that underlie the temporal organization of this activity differs greatly between the two circuits. The ability of neocortical network activity to drive a slow oscillation in the cerebellum supports the hypothesis that these two structures can be highly interrelated and interactive. Neocortically generated oscillations influence those of the cerebellum and other subcortical structures (Timofeev et al., 1996; Cowan and Wilson, 1994; Haslinger et al., 2006), in an anatomically and functionally specific manner, and may coordinate their activity and constantly tune their state of readiness and responsiveness (Petersen et al., 2003; Shu et al., 2003; Sachdev et al., 2004; Haider et al., 2006; Hasenstaub et al., 2007 ) to any input from the periphery or from other neocortical areas.

\section{References}

Aizenman CD, Linden DJ (1999) Regulation of the rebound depolarization and spontaneous firing patterns of deep nuclear neurons in slices of rat cerebellum. J Neurophysiol 82:1697-1709.

Albus J (1971) A theory of cerebellar function. Math Biosci 10:25-61.

Armstrong DM, Rawson JA (1979) Activity patterns of cerebellar cortical neurones and climbing fibre afferents in the awake cat. J Physiol 289:425-448.

Armstrong DM, Cogdell B, Harvey RJ (1979) Discharge patterns of Purkinje cells in cats anaesthetized with alpha-chloralose. J Physiol 291:351-366.

Ba AM, Guiou M, Pouratian N, Muthialu A, Rex DE, Cannestra AF, Chen JW, Toga AW (2002) Multiwavelength optical intrinsic signal imaging of cortical spreading depression. J Neurophysiol 88:2726-2735.

Baker SN, Pinches EM, Lemon RN (2003) Synchronization in monkey motor cortex during a precision grip task. II. Effect of oscillatory activity on corticospinal output. J Neurophysiol 89:1941-1953.

Barmack NH, Yakhnitsa V (2008) Functions of interneurons in mouse cerebellum. J Neurosci 28:1140-1152.

Bell CC, Grimm RJ (1969) Discharge properties of Purkinje cells recorded on single and double microelectrodes. J Neurophysiol 32:1044-1055.

Bengtsson F, Jörntell H (2007) Ketamine and xylazine depress sensoryevoked parallel fiber and climbing fiber responses. J Neurophysiol 98:1697-1705.

Bloedel JR, Roberts WJ (1971) Action of climbing fibers in cerebellar cortex of the cat. J Neurophysiol 34:17-31.

Bower JM, Beermann DH, Gibson JM, Shambes GM, Welker W (1981) Principles of organization of a cerebro-cerebellar circuit. Micromapping the projections from cerebral (SI) to cerebellar (granule cell layer) tactile areas of rats. Brain Behav Evol 18:1-18.

Brown IE, Bower JM (2002) The influence of somatosensory cortex on climbing fiber responses in the lateral hemispheres of the rat cerebellum after peripheral tactile stimulation. J Neurosci 22:6819-6829.

Buzsaki G (2006) Rhythms of the brain. New York: Oxford.

Chadderton P, Margrie TW, Häusser M (2004) Integration of quanta in cerebellar granule cells during sensory processing. Nature 428:856-860.

Chen G, Hanson CL, Ebner TJ (1996) Functional parasagittal compartments in the rat cerebellar cortex: an in vivo optical imaging study using neutral red. J Neurophysiol 76:4169-4174.

Contreras D, Steriade M (1995) Cellular basis of EEG slow rhythms: a study of dynamic corticothalamic relationships. J Neurosci 15:604-622.

Courtemanche R, Lamarre Y (2005) Local field potential oscillations in primate cerebellar cortex: synchronization with cerebral cortex during active and passive expectancy. J Neurophysiol 93:2039-2052.

Courtemanche R, Pellerin JP, Lamarre Y (2002) Local field potential oscillations in primate cerebellar cortex: modulation during active and passive expectancy. J Neurophysiol 88:771-782.

Cowan RL, Wilson CJ (1994) Spontaneous firing patterns and axonal pro- 
jections of single corticostriatal neurons in the rat medial agranular cortex. J Neurophysiol 71:17-32.

Crochet S, Petersen CC (2006) Correlating whisker behavior with membrane potential in barrel cortex of awake mice. Nat Neurosci 9:608-610.

de Solages C, Szapiro G, Brunel N, Hakim V, Isope P, Buisseret P, Rousseau C, Barbour B, Léna C (2008) High-frequency organization and synchrony of activity in the Purkinje cell layer of the cerebellum. Neuron 58:775-788.

De Zeeuw CI, Simpson JI, Hoogenraad CC, Galjart N, Koekkoek SK, Ruigrok TJ (1998) Microcircuitry and function of the inferior olive. Trends Neurosci 21:391-400.

De Zeeuw CI, Hoebeek FE, Schonewille M (2008) Causes and consequences of oscillations in the cerebellar cortex. Neuron 58:655-658.

Dieudonne S (1998) Submillisecond kinetics and low efficacy of parallel fibre-Golgi cell synaptic currents in the rat cerebellum. J Physiol 510:845-866.

Douglas RJ, Koch C, Mahowald M, Martin KA, Suarez HH (1995) Recurrent excitation in neocortical circuits. Science 269:981-985.

Dugué GP, Brunel N, Hakim V, Schwartz E, Chat M, Lévesque M, Courtemanche R, Léna C, Dieudonné S (2009) Electrical coupling mediates tunable low-frequency oscillations and resonance in the cerebellar Golgi cell network. Neuron 61:126-139.

Eccles JC, Llinás R, Sasaki K (1966a) The mossy fibre-granule cell relay of the cerebellum and its inhibitory control by Golgi cells. Exp Brain Res $1: 82-101$.

Eccles JC, Llinás R, Sasaki K (1966b) The excitatory synaptic action of climbing fibres on the Purkinje cells of the cerebellum. J Physiol 182:268-296.

Eccles JC, Llinás R, Sasaki K (1966c) The inhibitory interneurones within the cerebellar cortex. Exp Brain Res 1:1-16.

Eccles JC, Llinás R, Sasaki K (1966d) Parallel fibre stimulation and the responses induced thereby in the Purkinje cells of the cerebellum. Exp Brain Res 1:17-39.

Eccles JC, Ito M, Szentágothai J (1967) The cerebellum as a neuronal machine. New York: Springer.

Eccles JC, Faber DS, Murphy JT, Sabah NH, Taborikova H (1971) Afferent volleys in limb nerves influencing impulse discharges in cerebellar cortex. I. In mossy fibres and granule cells. Exp Brain Res 13:15-35.

Ferezou I, Bolea S, Petersen CC (2006) Visualizing the cortical representation of whisker touch: voltage-sensitive dye imaging in freely moving mice. Neuron 50:617-629.

Fernandez FR, Engbers JD, Turner RW (2007) Firing dynamics of cerebellar Purkinje cells. J Neurophysiol 98:278-294.

Grafstein B (1956) Mechanism of spreading cortical depression. J Neurophysiol 19:154-171.

Granit R, Phillips CG (1956) Excitatory and inhibitory processes acting upon individual Purkinje cells of the cerebellum in cats. J Physiol 133:520-547.

Haider B, Duque A, Hasenstaub AR, McCormick DA (2006) Neocortical network activity in vivo is generated through a dynamic balance of excitation and inhibition. J Neurosci 26:4535-4545.

Haider B, Duque A, Hasenstaub AR, Yu Y, McCormick DA (2007) Enhancement of visual responsiveness by spontaneous local network activity in vivo. J Neurophysiol 97:4186-4202.

Hámori J, Szentágothai J (1966) Identification under the electron microscope of climbing fibers and their synaptic contacts. Exp Brain Res $1: 65-81$.

Hartmann MJ, Bower JM (1998) Oscillatory activity in the cerebellar hemispheres of unrestrained rats. J Neurophysiol 80:1598-1604.

Hasenstaub A, Sachdev RN, McCormick DA (2007) State changes rapidly modulate cortical neuronal responsiveness. J Neurosci 27:9607-9622.

Haslinger R, Ulbert I, Moore CI, Brown EN, Devor A (2006) Analysis of LFP phase predicts sensory response of barrel cortex. J Neurophysiol 96: $1658-1663$.

Häusser M, Clark BA (1997) Tonic synaptic inhibition modulates neuronal output pattern and spatiotemporal synaptic integration. Neuron 19: 665-678.

Hurlock EC, McMahon A, Joho RH (2008) Purkinje-cell-restricted restoration of Kv3.3 function restores complex spikes and rescues motor coordination in Kcnc3 mutants. J Neurosci 28:4640-4648.

Isope P, Barbour B (2002) Properties of unitary granule cell $\rightarrow$ Purkinje cell synapses in adult rat cerebellar slices. J Neurosci 22:9668-9678.

Ito M (1984) The cerebellum and neural control. New York: Raven.
Jaeger D (2003) No parallel fiber volleys in the cerebellar cortex: evidence from cross-correlation analysis between Purkinje cells in a computer model and in recordings from anesthetized rats. J Comput Neurosci 14:311-327.

Jaeger D, De Schutter E, Bower JM (1997) The role of synaptic and voltagegated currents in the control of Purkinje cell spiking: a modeling study. J Neurosci 17:91-106.

Jörntell H, Ekerot CF (2002) Reciprocal bidirectional plasticity of parallel fiber receptive fields in cerebellar Purkinje cells and their afferent interneurons. Neuron 34:797-806.

Jörntell H, Ekerot CF (2006) Properties of somatosensory synaptic integration in cerebellar granule cells in vivo. J Neurosci 26:11786-11797.

Khaliq ZM, Gouwens NW, Raman IM (2003) The contribution of resurgent sodium current to high-frequency firing in Purkinje neurons: an experimental and modeling study. J Neurosci 23:4899-4912.

Leao AP (1944) Spreading depression of activity in the cerebral cortex. J Neurophysiol 7:359-390.

LeVay S, Gilbert CD (1976) Laminar patterns of geniculocortical projection in the cat. Brain Res 113:1-19.

Llinás R, Sugimori M (1980) Electrophysiological properties of in vitro Purkinje cell dendrites in mammalian cerebellar slices. J Physiol 305:197-213.

Llinás R, Nicholson C, Freeman JA, Hillman DE (1968) Dendritic spikes and their inhibition in alligator Purkinje cells. Science 160:1132-1135.

Loewenstein Y, Mahon S, Chadderton P, Kitamura K, Sompolinsky H, Yarom Y, Häusser M (2005) Bistability of cerebellar Purkinje cells modulated by sensory stimulation. Nat Neurosci 8:202-211.

Lu H, Hartmann MJ, Bower JM (2005) Correlations between Purkinje cell single-unit activity and simultaneously recorded field potentials in the immediately underlying granule cell layer. J Neurophysiol 94:1849-1860.

Maex R, De Schutter E (1998) Synchronization of golgi and granule cell firing in a detailed network model of the cerebellar granule cell layer. J Neurophysiol 80:2521-2537.

Magill PJ, Bolam JP, Bevan MD (2000) Relationship of activity in the subthalamic nucleus-globus pallidus network to cortical electroencephalogram. J Neurosci 20:820-833.

Marr D (1969) A theory of cerebellar cortex. J Physiol 202:437-470.

Marshall SP, Lang EJ (2004) Inferior olive oscillations gate transmission of motor cortical activity to the cerebellum. J Neurosci 24:11356-11367.

McKay BE, Engbers JD, Mehaffey WH, Gordon GR, Molineux ML, Bains JS, Turner RW (2007) Climbing fiber discharge regulates cerebellar functions by controlling the intrinsic characteristics of Purkinje cell output. J Neurophysiol 97:2590-2604.

Medina JF, Lisberger SG (2008) Links from complex spikes to local plasticity and motor learning in the cerebellum of awake-behaving monkeys. Nat Neurosci 11:1185-1192.

Mena-Segovia J, Sims HM, Magill PJ, Bolam JP (2008) Cholinergic brainstem neurons modulate cortical gamma activity during slow oscillations. J Physiol 586:2947-2960.

Middleton SJ, Racca C, Cunningham MO, Traub RD, Monyer H, Knöpfel T, Schofield IS, Jenkins A, Whittington MA (2008) High-frequency network oscillations in cerebellar cortex. Neuron 58:763-774.

Morissette J, Bower JM (1996) Contribution of somatosensory cortex to responses in the rat cerebellar granule cell layer following peripheral tactile stimulation. Exp Brain Res 109:240-250.

Napper RM, Harvey RJ (1988) Number of parallel fiber synapses on an individual Purkinje cell in the cerebellum of the rat. J Comp Neurol 274:168-177.

O'Connor SM, Berg RW, Kleinfeld D (2002) Coherent electrical activity between vibrissa sensory areas of cerebellum and neocortex is enhanced during free whisking. J Neurophysiol 87:2137-2148.

Palay SL, Chan-Palay VC (1974) Cerebellar cortex: cytology and organization. New York: Springer.

Palkovits M, Magyar P, Szentágothai J (1972) Quantitative histological analysis of the cerebellar cortex in the cat. IV. Mossy fiber-Purkinje cell numerical transfer. Brain Res 45:15-29.

Paré D, Shink E, Gaudreau H, Destexhe A, Lang EJ (1998) Impact of spontaneous synaptic activity on the resting properties of cat neocortical pyramidal neurons in vivo. J Neurophysiol 79:1450-1460.

Pellerin JP, Lamarre Y (1997) Local field potential oscillations in primate cerebellar cortex during voluntary movement. J Neurophysiol 78:3502-3507.

Peters A, Payne BR (1993) Numerical relationships between geniculocorti- 
cal afferents and pyramidal cell modules in cat primary visual cortex. Cereb Cortex 3:69-78.

Petersen CC, Hahn TT, Mehta M, Grinvald A, Sakmann B (2003) Interaction of sensory responses with spontaneous depolarization in layer $2 / 3$ barrel cortex. Proc Natl Acad Sci U S A 100:13638-13643.

Pinault D (1996) A novel single-cell staining procedure performed in vivo under electrophysiological control: morpho-functional features of juxtacellularly labeled thalamic cells and other central neurons with biocytin or neurobiotin. J Neurosci Methods 65:113-136.

Provini L, Redman S, Strata P (1968) Mossy and climbing fibre organization on the anterior lobe of the cerebellum activated by forelimb and hindlimb areas of the sensorimotor cortex. Exp Brain Res 6:216-233.

Raman IM, Bean BP (1997) Resurgent sodium current and action potential formation in dissociated cerebellar Purkinje neurons. J Neurosci 17:4517-4526.

Ramon y Cajal S (1904) Textura del sistema nervioso del hombre y los vertebrados. Madrid: Moya.

Rancz EA, Ishikawa T, Duguid I, Chadderton P, Mahon S, Häusser M (2007) High-fidelity transmission of sensory information by single cerebellar mossy fibre boutons. Nature 450:1245-1248.

Sachdev RN, Sellien H, Ebner FF (2000) Direct inhibition evoked by whisker stimulation in somatic sensory (SI) barrel field cortex of the awake rat. J Neurophysiol 84:1497-1504.

Sachdev RN, Ebner FF, Wilson CJ (2004) Effect of subthreshold up and down states on the whisker-evoked response in somatosensory cortex. J Neurophysiol 92:3511-3521.

Sanchez-Vives MV, McCormick DA (2000) Cellular and network mechanisms of rhythmic recurrent activity in neocortex. Nat Neurosci 3:1027-1034.

Santamaria F, Tripp PG, Bower JM (2007) Feedforward inhibition controls the spread of granule cell-induced Purkinje cell activity in the cerebellar cortex. J Neurophysiol 97:248-263.

Schonewille M, Khosrovani S, Winkelman BH, Hoebeek FE, De Jeu MT, Larsen IM, Van der Burg J, Schmolesky MT, Frens MA, De Zeeuw CI (2006) Purkinje cells in awake behaving animals operate at the upstate membrane potential. Nat Neurosci 9:459-461; author reply 461.

Shambes GM, Gibson JM, Welker W (1978) Fractured somatotopy in granule cell tactile areas of rat cerebellar hemispheres revealed by micromapping. Brain Behav Evol 15:94-140.

Shu Y, Hasenstaub A, McCormick DA (2003) Turning on and off recurrent balanced cortical activity. Nature 423:288-293.

Simpson JI, Hulscher HC, Sabel-Goedknegt E, Ruigrok TJ (2005) Between in and out: linking morphology and physiology of cerebellar cortical interneurons. Prog Brain Res 148:329-340.

Soteropoulos DS, Baker SN (2006) Cortico-cerebellar coherence during a precision grip task in the monkey. J Neurophysiol 95:1194-1206.

Steriade M, Contreras D, Curró Dossi R, Nuñez A (1993a) The slow $(<1$ $\mathrm{Hz}$ ) oscillation in reticular thalamic and thalamocortical neurons: scenario of sleep rhythm generation in interacting thalamic and neocortical networks. J Neurosci 13:3284-3299.

Steriade M, Nuñez A, Amzica F (1993b) Intracellular analysis of relations between the slow $(<1 \mathrm{~Hz})$ neocortical oscillation and other sleep rhythms of the electroencephalogram. J Neurosci 13:3266-3283.

Steriade M, Nuñez A, Amzica F (1993c) A novel slow ( $<1 \mathrm{~Hz}$ ) oscillation of neocortical neurons in vivo: depolarizing and hyperpolarizing components. J Neurosci 13:3252-3265.

Steriade M, Timofeev I, Grenier F (2001) Natural waking and sleep states: a view from inside neocortical neurons. J Neurophysiol 85:1969-1985.

Stern EA, Kincaid AE, Wilson CJ (1997) Spontaneous subthreshold membrane potential fluctuations and action potential variability of rat corticostriatal and striatal neurons in vivo. J Neurophysiol 77:1697-1715.

Thach WT Jr (1967) Somatosensory receptive fields of single units in cat cerebellar cortex. J Neurophysiol 30:675-696.

Timofeev I, Steriade M (1996) Low-frequency rhythms in the thalamus of intact-cortex and decorticated cats. J Neurophysiol 76:4152-4168.

Timofeev I, Contreras D, Steriade M (1996) Synaptic responsiveness of cortical and thalamic neurones during various phases of slow sleep oscillation in cat. J Physiol 494:265-278.

Timofeev I, Grenier F, Steriade M (2001) Disfacilitation and active inhibition in the neocortex during the natural sleep-wake cycle: an intracellular study. Proc Natl Acad Sci U S A 98:1924-1929.

Walsh JV, Houk JC, Mugnaini E (1974) Identification of unitary potentials in turtle cerebellum and correlations with structures in granular layer. J Neurophysiol 37:30-47.

Wilson CJ, Kawaguchi Y (1996) The origins of two-state spontaneous membrane potential fluctuations of neostriatal spiny neurons. J Neurosci 16:2397-2410.

Wilson CJ, Sachdev RN (2004) Intracellular and juxtacellular staining with biocytin. Curr Protoc Neurosci Chapter 1:Unit 1.12.

Witham CL, Baker SN (2007) Network oscillations and intrinsic spiking rhythmicity do not co-vary in monkey sensorimotor areas. J Physiol 580:801-814.

Yartsev MM, Givon-Mayo R, Maller M, Donchin O (2009) Pausing Purkinje cells in the cerebellum of the awake cat. Front Syst Neurosci 3:2. 